\title{
Characterization of L-band synthetic aperture radar (SAR) backscatter from floating and grounded thermokarst lake ice in Arctic Alaska
}

\author{
M. Engram ${ }^{1}$, K. W. Anthony ${ }^{1}$, F. J. Meyer ${ }^{2}$, and G. Grosse ${ }^{3}$ \\ ${ }^{1}$ Water and Environmental Research Center, Institute of Northern Engineering, University of Alaska Fairbanks, 306 Tanana \\ Loop, Fairbanks, AK 99775-7000, USA \\ ${ }^{2}$ Earth \& Planetary Remote Sensing, Geophysical Institute, University of Alaska Fairbanks, 903 Koyukuk Dr., Fairbanks, \\ AK 99775-7000, USA \\ ${ }^{3}$ Permafrost Laboratory, Geophysical Institute, University of Alaska Fairbanks, 903 Koyukuk Dr., Fairbanks, AK \\ 99775-7000, USA
}

Correspondence to: M. Engram (melanie.engram@alaska.edu)

Received: 6 April 2013 - Published in The Cryosphere Discuss.: 22 May 2013

Revised: 13 September 2013 - Accepted: 7 October 2013 - Published: 14 November 2013

\begin{abstract}
Radar remote sensing is a well-established method to discriminate lakes retaining liquid-phase water beneath winter ice cover from those that do not. L-band $(23.6 \mathrm{~cm}$ wavelength) airborne radar showed great promise in the 1970s, but spaceborne synthetic aperture radar (SAR) studies have focused on C-band $(5.6 \mathrm{~cm})$ SAR to classify lake ice with no further attention to L-band SAR for this purpose. Here, we examined calibrated L-band single- and quadraturepolarized SAR returns from floating and grounded lake ice in two regions of Alaska: the northern Seward Peninsula (NSP) where methane ebullition is common in lakes and the Arctic Coastal Plain (ACP) where ebullition is relatively rare. We found average backscatter intensities of $-13 \mathrm{~dB}$ and $-16 \mathrm{~dB}$ for late winter floating ice on the NSP and ACP, respectively, and $-19 \mathrm{~dB}$ for grounded ice in both regions. Polarimetric analysis revealed that the mechanism of L-band SAR backscatter from floating ice is primarily roughness at the ice-water interface. L-band SAR showed less contrast between floating and grounded lake ice than C-band; however, since L-band is sensitive to ebullition bubbles trapped by lake ice (bubbles increase backscatter), this study helps elucidate potential confounding factors of grounded ice in methane studies using SAR.
\end{abstract}

\section{Introduction and background}

Thermokarst (thaw) lakes are abundant in arctic and subarctic permafrost lowlands, comprising more than $40 \%$ of the land area in some regions (Grosse et al., 2013). Formed by thermal degradation of permafrost and melting of ground ice, thermokarst lakes range in depth from one to two meters to more than $10 \mathrm{~m}$, largely depending on the ice content of the permafrost in the region and on lake age.

Seasonal ice-cover typically starts forming on lake surfaces in late October or early November in Arctic Alaska and grows to a maximum thickness of over one meter to two meters by late March/early April (Mellor 1982; Jeffries et al., 1994; Arp et al, 2011). Some lakes are shallower than 1-2 m and no liquid water remains at maximum seasonal ice thickness, resulting in grounded ice. In lakes that are deeper than the maximum ice thickness, liquid water remains under the thick ice cover all winter (floating ice). Other lakes have a shallow littoral region and freeze to the lake bed close to the shore, while ice floats on liquid-phase water in deeper lake centers.

Distinguishing whether or not lakes freeze completely to the lake bed is useful for a multitude of reasons: to identify the over-wintering habitats of fish, to identify winter water availability for domestic water supplies to rural villages or for winter ice road construction, and to determine which lakes show a water level change. Ice monitoring from year 
to year can be used as an indicator of climate change (Hall et al., 1994; Morris et al., 1995; Surdu et al., 2013), serves as a measure of the water balance and the impacts of local disturbances, such as lake drainage, and provides an indicator of permafrost health, since an increase in floating lakeice area alters the heat flux of thermokarst-lake landscape regimes (Jeffries, et al., 2002; Arp et al., 2011, 2012).

A brightness contrast in radar images from floating lake ice versus grounded lake ice was first discovered in the late 1970s with X-band Side Looking Airborne Radar (SLAR) (Sellmann et al., 1975; Elachi et al., 1976; Weeks, 1977) when coastal land areas with lakes were imaged during seaice imaging missions. At least two SLAR missions used Lband as well as X-band microwave and qualitative examination of radar images found that both wavelengths showed floating ice as bright and grounded ice as dark (Elachi et al., 1976; Sellmann et al., 1977). Elachi et al. (1976) noticed a larger contrast between floating and grounded ice from Lband than X-band in uncalibrated SLAR, suggesting that Lband radar could be a useful indicator of grounded vs. floating ice.

The same phenomenon of high-backscatter return from floating ice and low return from grounded ice was observed in the early 1990s with the advent of calibrated spaceborne SAR, using the C-band VV microwave signal of ERS-1 and ERS-2 (Jeffries et al., 1994; Morris et al., 1995; French et al., 2004). Others have observed this difference using Radarsat1 C-band HH data (Duguay et al., 2002; Hirose et al., 2008; Arp et al., 2011). Duguay et al. (2002) additionally examined the effect of a varying incidence angle on lake-ice observations and found that a steeper incidence angle $\left(20^{\circ}-35^{\circ}\right)$ provided higher backscatter values from floating ice than a shallow incidence angle $\left(35^{\circ}-49^{\circ}\right)$ for calibrated C-band $\mathrm{HH}$ $\mathrm{SAR}$, and that this difference was more pronounced from ice with fewer tubular bubbles. For C-band SAR, backscatter intensity after initial ice formation is very low $(<-15 \mathrm{~dB})$, and cracks in thin ice can be detected (Hall et al., 1994); however, SAR intensity quickly increases as ice thickens throughout the winter to reach a ceiling of -6 to $-7 \mathrm{~dB}$ for floating ice. If lake ice grows thick enough to completely ground to the lake bed, the C-band SAR backscatter intensity is low $(-14$ to $-18 \mathrm{~dB}$ ). Evaluating high or low C-band SAR backscatter from lake ice has become an established method for determining whether a lake retains floating ice all winter or if lake ice is frozen completely to the lake bed in arctic and subarctic lakes (Jeffries et al., 1996; French et al., 2004; White et al., 2008; Arp et al., 2012). After a thorough literature search, we could not find any detailed reports that characterized Lband calibrated SAR backscatter intensity from floating and grounded lake ice to follow the early potential that Elachi et al. (1976) reported from L-band airborne radar.

One of the main drivers of radar backscatter intensity is the dielectric constant of the target. Liquid water has a very large real dielectric constant $(\varepsilon /)$ compared to ice, so the water-ice interface with its high dielectric contrast has been an obvious explanation for part of the radar return from floating ice. For L-band, $\varepsilon \approx 88$ for cold water (Skolunov, 1997) and for Cband, $\varepsilon^{\prime} \approx 69$, while ice has a dielectric constant of about 3.2 for both C and L-band wavelengths (Leconte et al., 2009). Because of this large difference in the magnitude of $\varepsilon^{\prime}$ for ice and water, there is a strong reflectance of L-band and Cband microwave from the water-ice interface which disappears when the lake ice freezes to the ground.

A smooth liquid water surface will reflect microwaves away from the receiving antenna on the satellite due to specular reflection, as demonstrated by calm open water or by newly frozen lakes that appear black in a SAR image. An additional reflector must be present for energy to be turned once again and reflected back to the satellite. Weeks (1978, 1981) and others (Jeffries et al., 1994; Mellor, 1982; Morris et al., 1985, Duguay et al., 2002) have posited that the small ( $<2 \mathrm{~mm}$ diameter) tubular bubbles formed in lake ice by the rejection of dissolved gasses during the freezing process (Gow and Langson, 1977, Boereboom et al., 2012) play a role in turning radar back to the satellite. Similarly, Engram et al. (2012) showed a positive correlation between L-band backscatter and the abundance of larger (usually $1-100 \mathrm{~cm}$ diameter) ebullition bubbles in ice-covered lakes. The same study demonstrated that this positive correlation between single-pol L-band SAR and field measurements of ebullition bubbles in frozen lakes did not exist for C-band VV SAR. Further, they used a polarimetric decomposition to posit that free-phase gas bubbles trapped under ice create a rough surface that interacts with Band 3 of the Pauli decomposition (Cloude and Pottier, 1996), resulting in a strong reflectance back to the satellite.

It should be noted that some dark areas on lake ice in uncalibrated C-band SAR images have been documented for floating ice on deep lakes $(130 \mathrm{~m})$ in Montana, USA (Hall et al., 1994). Hall et al. attributed these dark areas to thinner ice in zones of the lake that had more snow cover and to the different stratigraphy of small tubular bubbles in lake ice than that of northern Alaskan thermokarst lakes. Lakes in more temperate climates have later freeze-up, thinner ice, slower ice growth, possibly more white ice, different patterns of tubular bubbles (Hall et al., 1994) and possibly more thawing and re-freezing events during the winter. Dark areas of low backscatter return from these lakes would not indicate grounded ice, but could instead indicate thin, newly-formed ice or ice without small tubular bubbles near the ice-water interface (Hall et al., 1994).

Determining which combination of SAR parameters of wavelength, incidence angle and polarization works best to distinguish between floating and grounded lake ice is an important precondition for targeted or operational lake-ice studies. SAR, as an active instrument, does not continually acquire data and SAR satellites have a finite lifetime. These two factors result in temporal imaging gaps by particular sensors in data archives. The resulting history of available SAR data over any particular area is therefore often a mixture of 


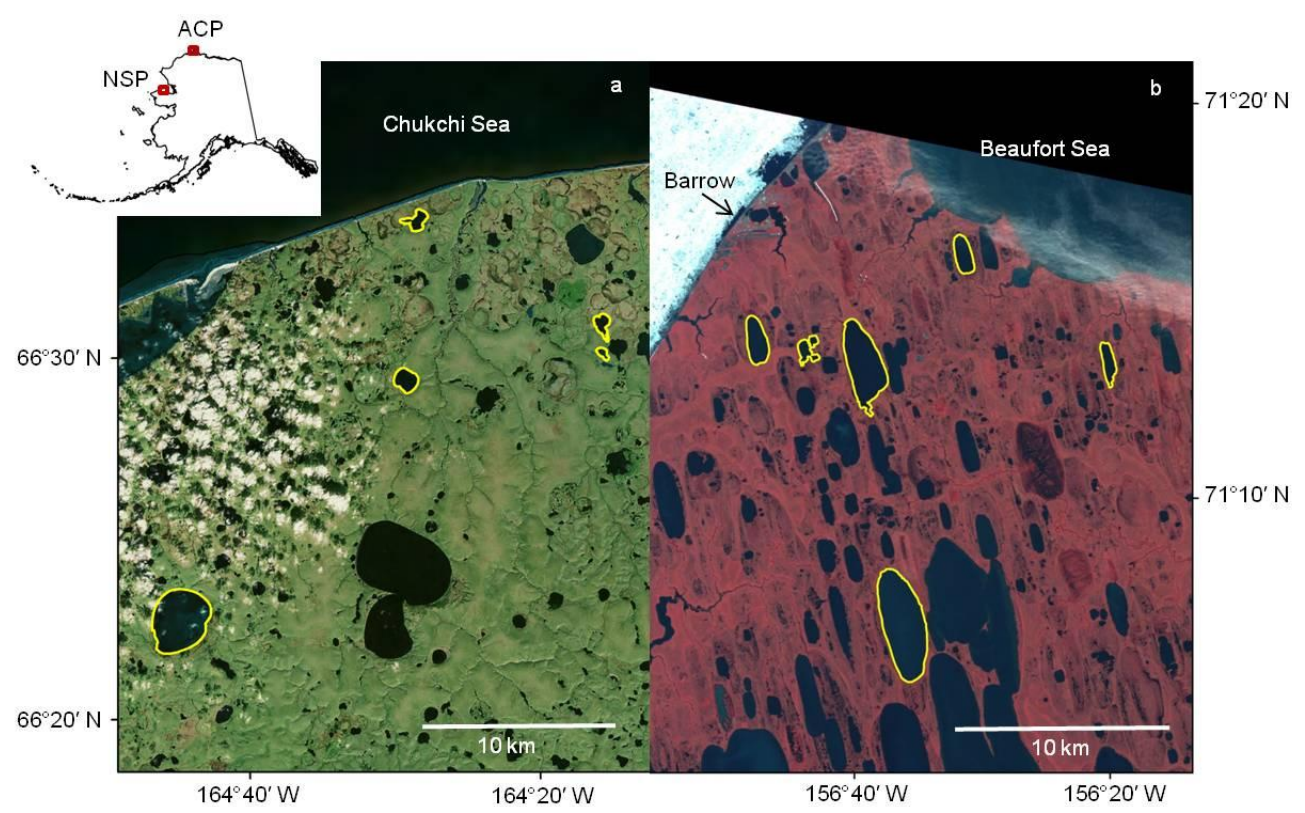

Fig. 1. Study lakes are highlighted in yellow on (a) northern Seward Peninsula (NSP) and (b) Arctic Coastal Plain (ACP) south of Barrow. In panel (a) the large lake in the lower left is Whitefish Maar and the double-lobed lake in the center bottom is Devil Mountain Maar, both of volcanic origin; all other study lakes in both regions are of thermokarst origin. Panel (a) is a Spot 5 mosaic from the Geographic Information Network of Alaska and panel (b) is a scene from 10 July 2008 AVNIR-2 (Advanced Visible and Near Infrared Radiometer type 2).

$\mathrm{X}$-, C- and L-bands with different incidence angles, polarizations, and acquisition times. It is important to characterize L-band SAR intensity values from known floating and grounded lake ice, in addition to the established work published in C-band, in case L-band acquisitions are the only available SAR data. It is furthermore important to study the driving scattering mechanism for scattering in the L-band frequency range in order to better understand the interaction of SAR with lake ice, and in order to identify observation parameters that optimize the contrast between floating and grounded ice. Finally, the magnitude of backscatter intensity decrease that suddenly occurs when lakes freeze to the lake bed is important to know in order to eliminate lakes that exhibit a backscatter drop of this magnitude from lake-ice analyses targeting methane ebullition (Engram et al., 2012).

Here we examine the value of single-polarized (singlepol) L-band HH backscatter from floating and grounded lake ice. We also use a polarimetric decomposition of quadraturepolarized (quad-pol) SAR data from the Advanced Land Observing Satellite (ALOS) PALSAR L-band SAR to ascertain which scattering mechanism (roughness, double-bounce or volumetric scattering) or combination of mechanisms is displayed by floating lake ice. We characterize the difference in L-band backscatter intensity between floating ice and grounded ice for single-pol (HH) and the $T 11, T 22$ and $T 33$ polarimetric elements from the coherency matrix of a decomposed quad-pol SAR signal (Lee and Pottier, 2009), and the corresponding dominant scattering mechanism for floating ice for L-band SAR. We discuss morphology at the ice-water interface as seen in field experiments with lake ice in Fairbanks, Alaska, and consider two physical explanations for the dominant L-band SAR scattering mechanism, as seen from a polarimetric decomposition. We compare Lband backscatter intensity values to those of the established C-band VV SAR to determine the utility of L-band SAR in distinguishing between grounded and floating ice, and to possibly gain more understanding of ice-microwave interactions at various wavelengths and polarizations. Finally, we use statistics to test whether mean backscatter intensity of lake ice is equal two different regions of Alaska.

\section{Methods}

We extracted backscatter values from SAR images of floating and grounded ice from lakes in two regions in Alaska, USA: the northern Seward Peninsula (NSP) $\left(\approx 66.5^{\circ} \mathrm{N}, 164.4^{\circ} \mathrm{W}\right.$; five lakes) and the Arctic Coastal Plain (ACP), south of Barrow, Alaska $\left(\approx 71.2^{\circ} \mathrm{N}, 156.6^{\circ} \mathrm{W}\right.$; six lakes) (Fig. 1). Both are coastal regions (Fig. 1), but they differ in permafrost and climatic characteristics and therefore contain two distinct types of thermokarst lakes. Permafrost on the northern Seward Peninsula is generally less thick (ca. $100 \mathrm{~m}$ ) than on the Arctic Coastal Plain (up to $600 \mathrm{~m}$ ) (Jorgenson et al., 2008). The near-surface layer of ice-rich permafrost is thicker $(>20 \mathrm{~m}$ ) on the northern Seward Peninsula (West and Plug, 2008) than on the Arctic Coastal Plain $(<5 \mathrm{~m})$ (Jorgenson and Shur, 2007), resulting in deeper lakes when ground 
ice melts. The deep soil organic carbon stocks in the ice-rich Yedoma deposits on the northern Seward Peninsula potentially are also higher than soil carbon stocks in the deeper marine, fluvial, and eolian deposits on the Arctic Coastal Plain (Walter Anthony unpublished data). As a result, thermokarst lakes on the northern Seward Peninsula have a higher rate of methane production, resulting in a larger abundance (1.8 seeps-meter ${ }^{-2}$ ) of ebullition bubbles trapped in and under lake ice (Walter Anthony and Anthony, 2013). In contrast, lakes south of Barrow on the Arctic Coastal Plain have significantly fewer ebullition bubbles $\left(0.4\right.$ seeps-meter $\left.{ }^{-2}\right)$ included in their ice cover (Walter Anthony et al., 2012; Walter Anthony and Anthony, 2013). Bubble density was determined from field data from NSP in fall 2008 and ACP in fall 2009. Including lakes with both high and low numbers of ebullition bubbles was important to this study since ebullition may be a confounding factor in isolating floating and grounded ice values in L-band imagery.

Field data on lake-ice thickness, water depth and sediment characteristics were collected for 10 locations on four NSP thermokarst lakes in April 2009 that varied both in bathymetry (deep vs. shallow) and in levels of ebullition bubbles observed previously by Engram et al. (2012) in field work. We measured ice thickness in auger holes and water depth using sonar (Vexilar LPS-1 Hand-Held Depth Finder) and a weighted measuring tape. Lake sediments were retrieved with a percussion hammer corer (Farquharson, 2012). In addition to thermokarst lakes, we included in this study the larger Whitefish Maar, a $6 \mathrm{~m}$ deep lake on the NSP of volcanic origin that does not freeze to the bottom in the center (Hopkins et al., 1988). We identified areas of grounded and floating ice on the NSP study lakes using these field measurements of grounded and floating ice in April 2009, coincident with SAR imagery, and by using recent ERS- 2 image interpretation. To identify areas of lakes with grounded vs. floating lake ice on the ACP, we used the ERS-2 signal together with field data and remote sensing data from previous publications of C-band VV signal for floating and grounded ice (Mellor, 1983; Jeffries, 1996). Five of the six Arctic Coastal Plain study lakes were featured in early radar research (Sellmann et al., 1975; Mellor, 1982; Jeffries et al., 1994). We chose one additional lake to increase the sample sizes of lakes with either floating or grounded ice based on recent ERS-2 SAR imagery.

We sampled pixels from L-band Japanese Earth Resources Satellite -1 (JERS-1) scenes from 1993 to 1998 and from both single- and quad-pol L-band PALSAR scenes acquired during 2008-2011 in spring (late March to early April; Table 1). We selected this spring time frame because it represents the period of maximum lake-ice thickness while preceding the onset of melting. ERS-1 and ERS-2 C-band SAR scenes were selected based on acquisition dates closest to L-band SAR acquisitions for verification of grounded lake-ice conditions and for comparison of L-band with C-band SAR. The $\mathrm{C}$-band scenes were generally acquired on either the same day or just a few days apart from L-band acquisitions, except in two cases where a week or more lapsed between acquisitions from the different sensors (Table 1).

We used PolSARpro software (v. 4.2.0) to decompose quad-pol L-band images into the $3 \times 3$ complex coherency matrix [ $\mathbf{T}_{3}$ ], and compared the $T 11, T 22$, and $T 33$ elements of the coherency matrix (Lee and Pottier, 2009) to SAR single-pol intensity values (Gao, 2010). The $T 11, T 22$ and $T 33$ polarimetric elements are equivalent to the spatially averaged versions of Band 3, Band 1, and Band 2 of a Pauli decomposition (Claude and Pottier, 1996), although generally the Pauli bands are expressed as amplitude, which is the square root of the intensity images used in this study. Polarimetric decompositions, such as the Pauli decomposition, provide information about the scattering mechanisms of point and distributed targets by examining the polarization state of transmitted and received energy with the complex scattering matrix [S] (Cloude, 2010; van Zyl and Kim, 2010).

Using all of the pixels from a lake is not useful if lake ice is partially grounded and partially floating. Some shallow lakes freeze completely to the lake bed over the entire lake area and appear dark in a SAR image. Other lakes are deep enough that no part of the lake freezes to the bottom except a narrow border near the shore that is less than one pixel and therefore not visible in SAR imagery. Still other lakes have wide shallow littoral zones that freeze completely to the lake bed while ice in deeper areas of the lake remains floating, producing a dark lake margin in a SAR image with a bright lake center. To exclude mixed pixels with grounded and floating ice from the analysis, we developed a supervised selection method to identify a large number of pixels that were either entirely floating or grounded ice from the same locations within lakes on co-registered SAR images. Using field measurements of ice-thickness and lake depth from April 2009 and manual interpretation of ERS-2 imagery, we classified areas of frozen lakes for both study sites as (1) grounded ice, (2) floating ice, or (3) an ambiguous area. We created straight lines in GIS within a particular ice type (floating or grounded) on an ERS-1 or -2 image, then sampled near-uniformly spaced points along these sample lines using bilinear interpolation (Fig. 2). For consistency, the number of pixels we sampled was related to lake area: we created sample lines so that the ratio of sample line length to lake area was 25-35 meters per square kilometer of lake surface. The resulting spacing between sample lines and between uniformly spaced points ensured that $18 \mathrm{~m}$ pixels would not be sampled twice. This method of supervised sampling allowed us to preclude ambiguous portions of lakes that could not be classified, using C-band SAR images, as either floating or grounded ice. We refined the geolocation of the SAR images in GIS using lateral translation to ground control points, then selected pixels from the same geographic locations on each SAR image in the stack with uniform points along sample lines with the ArcGIS $^{\mathrm{TM}}$ Sample Tool. 
Table 1. SAR data were selected based on data availability over two study areas for late March-April from 1993 through 2011.

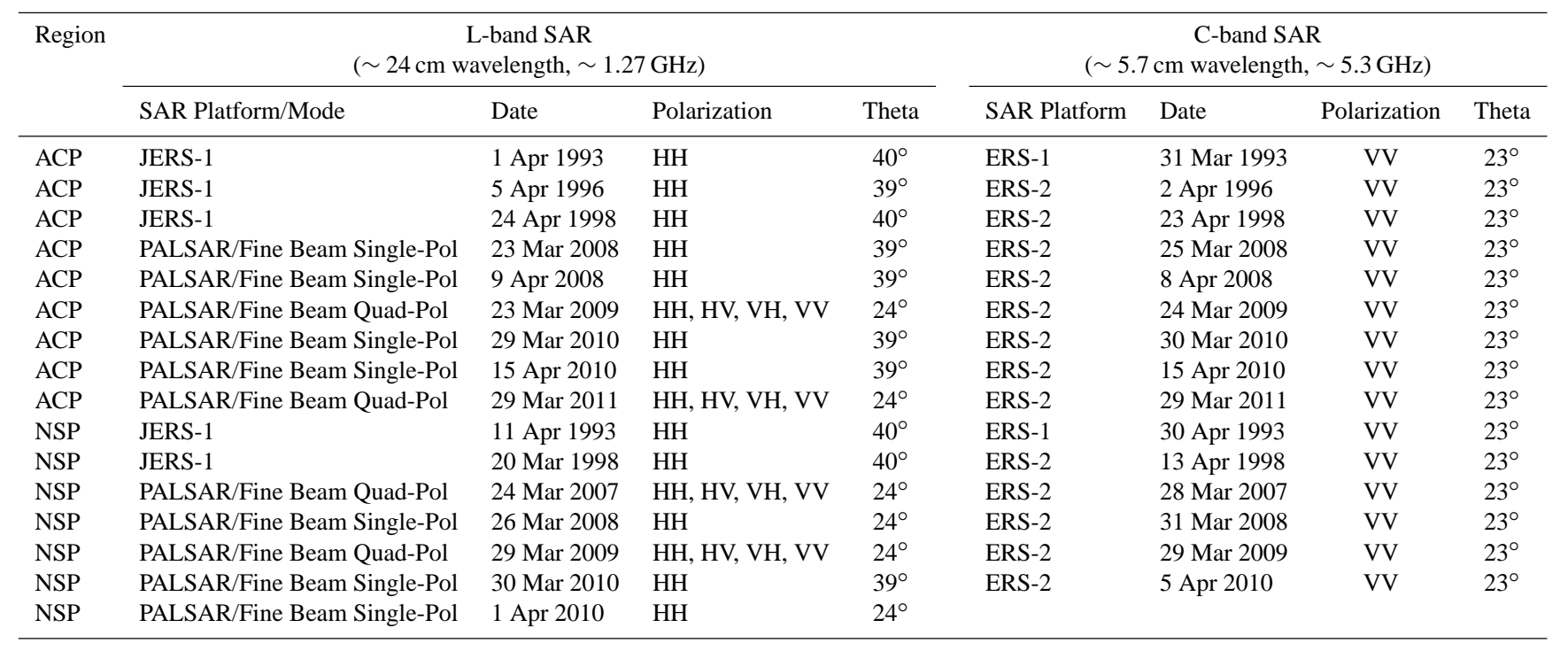

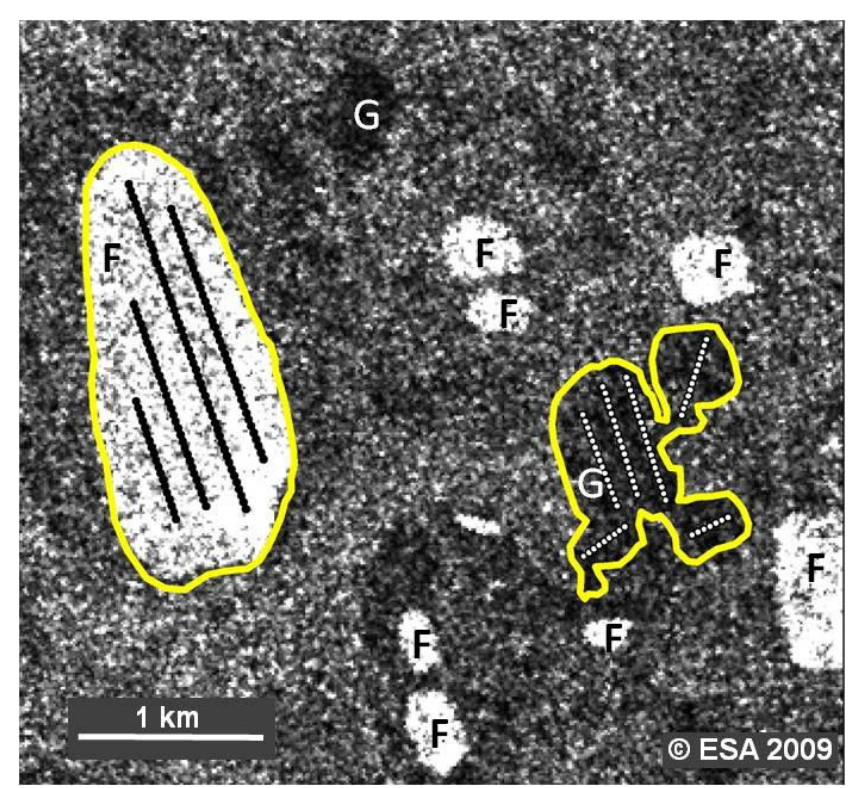

Fig. 2. C-band VV SAR image of thermokarst lakes on the Arctic Coastal Plain (ACP), Alaska. High backscatter from floating lake ice is indicated by "F" while low backscatter from grounded lake ice is indicated by "G". Two study lakes are outlined in yellow and pixel sampling locations are rows of uniformly spaced points, shown in contrasting color.

We used the Shapiro-Wilk Test to determine normality on all data distributions. To determine inter-region variability, we compared both grounded and floating-ice backscatter between our two study regions using a statistical $t$ test for each SAR imaging parameter (wavelength-polarization combinations). All statistics were determined by SPSS (v. 19) software. To determine which SAR wavelength-polarization combination was most useful to distinguish floating and grounded lake ice, we compared the difference between floating and grounded lake-ice backscatter values to find the SAR imaging parameters that exhibited the most contrast.

During the timeframe of this study, 1993-2011, we noticed that many lakes flipped from springtime grounded-ice to floating-ice status and a few changed from floating-ice to grounded-ice status. Some lakes in the ACP region froze to the bottom in the 1990s but no longer freeze to the bottom in the late 2000s (based on recent C-band SAR data). One of the study lakes, West Twin Lake, was frozen to the lake bed in the 1992 and 1998 spring images, but in 2008 spring images, C-band radar backscatter of about $-6 \mathrm{~dB}$ signified floating ice. This could be explained by warmer winters, or winters with more insulating snowfall in the more recent past (Walsh et all., 1998; Duguay et al., 2003; Brown and Duguay, 2010; Arp et al., 2012; Surdu et al., 2013). Consequently, pixels from West Twin Lake were classified as grounded ice until 2008, but as floating ice thereafter. Another study lake on the ACP, Kimouksik Lake, was a floating-ice lake in 1993, but low SAR backscatter evinced Kimouksik ice was freezing to the bottom in 2008. This switch from floating ice to grounded ice was a result of a change in water level due to the draining of an adjacent lake between 1992 and 2002. The hydrological changes of this lake are well documented in Jones (2006). Pixels from Kimouksik Lake were classified as floating ice in 1993, but as grounded ice thereafter.

Other important field work included a controlled experiment in which we simulated ebullition events in a humanmade lake with no natural ebullition in order to observe the effect of gas bubbles trapped by lake ice on the topography of the ice underside. O'Grady Pond $\left(64.847^{\circ},-147.803^{\circ}\right)$, a $20 \mathrm{~m}$ deep gravel pit in Fairbanks, Alaska, is used by Ice Alaska to harvest bubble-free ice blocks for ice sculpting. 

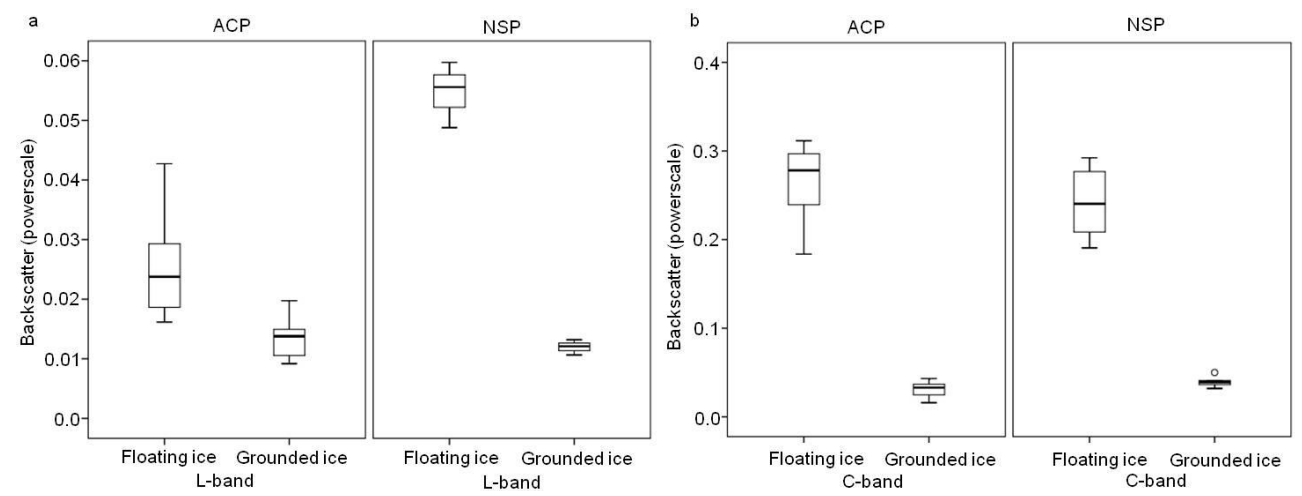

Fig. 3. Boxplots of mean backscatter intensity of all floating and grounded ice from study lakes for each SAR scene from (a) L-band and (b) C-band. No statistical far-outliers and only one near outlier (panel a NSP, ERS-1, 30 April 1993) indicate that SAR backscatter values from floating and grounded ice in late March-April are similar from year to year. Note different scales on $y$ axis for (a) and (b).

Although O'Grady Pond is deeper than many thermokarst lakes, we assumed that deep water would not have a different effect on gas bubbles freezing into surface ice than would a shallow lake. Choosing a lake with no naturally occurring gas ebullition allowed us to control the timing and size of gas bubbles artificially introduced for freezing into the ice column. In March 2013, we shoveled snow off an area of ice on the pond where the ice had been previously removed on 20 January 2013 by Ice Alaska. Following the initial ice harvest, the ice sheet refroze as clear black ice with a thickness of $27 \mathrm{~cm}$ by 16 March 2013. We augured a hole and inserted a plastic tube under the ice attached to a pole $2 \mathrm{~m}$ long to allow bubbles to rise in the water column prior to coming to rest under the ice surface as they would in naturally occurring ebullition events. We used air to create bubbles under the ice with a small compressor and a check valve. It should be noted that the flux rate in some of the simulated ebullition events was faster and more short-lived than most flux rates observed in natural ebullition events. We simulated two types of ebullition events. In one plot we released a very low volume of gas that formed bubbles approximately one to three centimeters in diameter. In a second plot we released a larger volume of gas that formed a bubbles on the underside of the ice approximately 10 to 30 centimeters in diameter. We returned to create additional layers of bubbles on 17, 21 and 26th March. We harvested blocks of ice from both areas on 29th March to observe how the rate of ice growth was affected by the insulation of gas bubbles, and to reveal the resulting shape of the underside of the lake ice.

\section{Results}

SAR backscatter values were consistent between years for late March-April scenes for all imaging parameters: boxplots of distributions showed no far-outliers, and only one case of a near outlier (Fig. 3). Backscatter values of sampled pixels for floating and grounded ice averaged from individual lakes in each SAR scene were normally distributed (ShapiroWilk, $\alpha=0.05$ ).

We observed that lake sediments in both study regions consisted of organic rich fine-grained sediments (Farquharson, 2012; Walter Anthony and Grosse, unpublished data).

From floating lake-ice, L-band single-pol (HH) backscatter values showed statistically significant regional variability and were higher on the NSP $(-13 \mathrm{~dB})$ than the ACP $(-16 \mathrm{~dB})$. The roughness polarimetric element $(T 11)$ of quad-pol L-band SAR was the highest returned signal for floating ice for L-band SAR with a mean backscatter of $-9 \mathrm{~dB}$ on the NSP and $-12 \mathrm{~dB}$ on the ACP. In comparison, the values of the polarimetric elements representing doublebounce (T22) and volumetric scattering (T33) were low for floating ice in both regions: $-17 \mathrm{~dB}$ to $-20 \mathrm{~dB}$ for $T 22$, and $-21 \mathrm{~dB}$ to $-24 \mathrm{~dB}$ for $T 33$ (Table 2 and Fig. 4). Polarimetric element $T 11$ (roughness) was significantly higher for floating ice from lakes in the NSP than from lakes in the ACP ( $p<0.01$ ), but $T 22$ (double-bounce) and $T 33$ (volumetric) were lower from floating ice in the NSP than ACP (Table 2 and Fig. 4). C-band VV backscatter values for floating ice were statistically identical for both regions $(-6 \mathrm{~dB})$ and substantially higher than L-band values for single-pol and all polarimetric scattering components (Table 2).

From grounded-ice, SAR backscatter intensity was very low $(<-14 \mathrm{~dB})$ for all imaging parameters for both NSP and ACP regions (Fig. 4). The average SAR radar cross section of grounded ice for single-pol L-band was $-19 \mathrm{~dB}$ for both ACP and NSP (Table 2). This was significantly lower than the average $\mathrm{C}$-band grounded ice intensity of $-15 \mathrm{~dB}$ for ACP and $-14 \mathrm{~dB}$ for NSP $(p<0.01)$. Backscatter intensity from quad-pol L-band SAR for grounded lake ice, when decomposed into polarimetric elements, was highest $(-16 \mathrm{~dB})$ for $T 11$ (roughness) for both regions, intermediate for $T 22$ (double-bounce) with $-20 \mathrm{~dB}(\mathrm{ACP})$ and $-23 \mathrm{~dB}$ (NSP), and lowest for $T 33$ (volume scattering) with $-25 \mathrm{~dB}$ (ACP) and $-27 \mathrm{~dB}$ (NSP) (Table 2). A $t$ test failed to reveal 
Table 2. Summary of mean SAR backscatter intensity $(\mathrm{dB})$ from floating and grounded lake ice for L- and C-bands from both study regions.

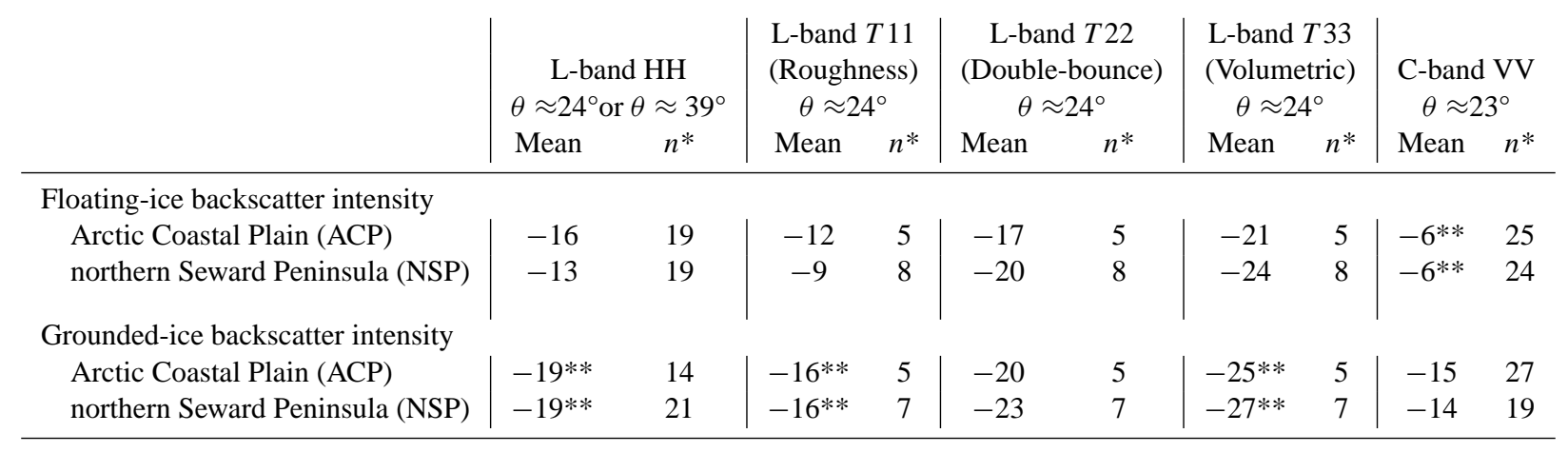

* Sum of sampled lakes counted from each SAR scene

**Denotes that a $t$ test did not reveal a statistically significant difference between the mean backscatter from the ACP and the NSP.

a statistically significant difference between the two regions for grounded ice in L-band HH, L-band $T$ 11(roughness), and T33(volumetric); therefore we assumed equal means (Table 2). Another $t$ test showed that the average radar brightness of grounded ice on the ACP was not different for the Lband $T 11$ (roughness) component and C-band. On the NSP, however, means of these two parameters for grounded ice were statistically different $(p<0.01)$. Backscatter intensity from grounded ice on the ACP was significantly different than from the NSP for C-band $(p<0.01)$ and L-band $T 22$ (double-bounce) $(p<0.04)$.

The contrast (arithmetic difference) between floating and grounded ice SAR backscatter was determined by subtracting the grounded-ice sigma-naught backscatter intensity value from that of floating ice, using linear powerscale units. L-band $\mathrm{HH}$ mean intensity difference between floating and grounded ice was 0.035 on the NSP and 0.009 on the ACP. These single-pol L-band powerscale values, when converted to decibel log-scale, were the difference between the mean floating and grounded ice intensities of $-13 \mathrm{~dB}$ and $-19 \mathrm{~dB}$ on the NSP, $-16 \mathrm{~dB}$ and $-19 \mathrm{~dB}$ on the ACP (Table 2). Lband $\mathrm{HH}$ contrast between floating and grounded ice in both regions was much lower than C-band contrast. While the logarithmic scale of decibels prohibits directly subtracting $\mathrm{dB}$ values, the $\mathrm{C}$-band contrast was the result of the difference between the floating-ice mean of $-6 \mathrm{~dB}$ to the grounded ice mean of $-14 \mathrm{~dB}$ and $-15 \mathrm{~dB}$ for lakes on the NSP and ACP, respectively.

For all decomposed elements of quad-pol L-band data, backscatter from grounded ice was always lower than from floating ice, but the difference in powerscale units between floating and grounded ice was very small (from $-17 /-20 \mathrm{~dB}$ to $-20 /-23 \mathrm{~dB}$, ACP/NSP) for $T 22$ (double-bounce) and even smaller $(-21 /-24 \mathrm{~dB}$ to $-24 /-27 \mathrm{~dB}$ ACP/NSP) for $T 33$ (volumetric). The difference between the means of floating and grounded ice for $T 11$ (roughness) was largest of the three polarimetric elements, a difference of 0.05 (from -12 to $-16 \mathrm{~dB}$ ) for the $\mathrm{ACP}$, and 0.10 (from -9 to $-16 \mathrm{~dB}$ ) for the NSP (Fig. 5).

Results from our ebullition simulation field experiment where gas was injected under lake ice at irregular intervals over 14 days, then blocks of ice were harvested to observe ice-bubble stratigraphy and ice morphology, showed that the insulation properties of gas bubbles from ebullition caused upward indentations, or "tenting" on the bottom surface of the ice (Fig. 6). In the plot where we created small diameter $(1-3 \mathrm{~cm})$ bubbles, this "tenting" or creation of upwardpointing round-tipped, conic shapes in the ice occurred below only a few columns of bubbles. The bottoms of other bubble columns were relatively flat. In the plot with larger diameter bubbles $(10-30 \mathrm{~cm})$ upward "tenting" where ice growth was slower beneath the insulating gas was observed under every bubble column. These "tents", or upward bulges in the ice, were identical in scale and shape to others we observed in natural ebullition settings in both deep and shallow thermokarst lakes.

\section{Discussion}

Floating-ice values from polarimetric roughness parameter $T 11$ indicate that roughness appears to be the dominant scattering mechanism in L-band for floating lake-ice in these two permafrost regions (Fig. 4b). The contributions from double-bounce and volumetric scattering are both significantly smaller. If the high intensity of the roughness component remained the same after ice froze to the bottom, the roughness could be explained by rough air-ice surface, or roughness within the ice. But that is not the case: the $T 11$ component decreases (and decreases the most of the three polarimetric elements) when the lake freezes to the bottom. Therefore, the roughness must involve the high dielectric contrast of the ice-water interface which is present in floating ice and is absent in grounded ice. While Engram et al. (2012) found that roughness was the main component of high backscatter intensity from floating ice for L-band and 

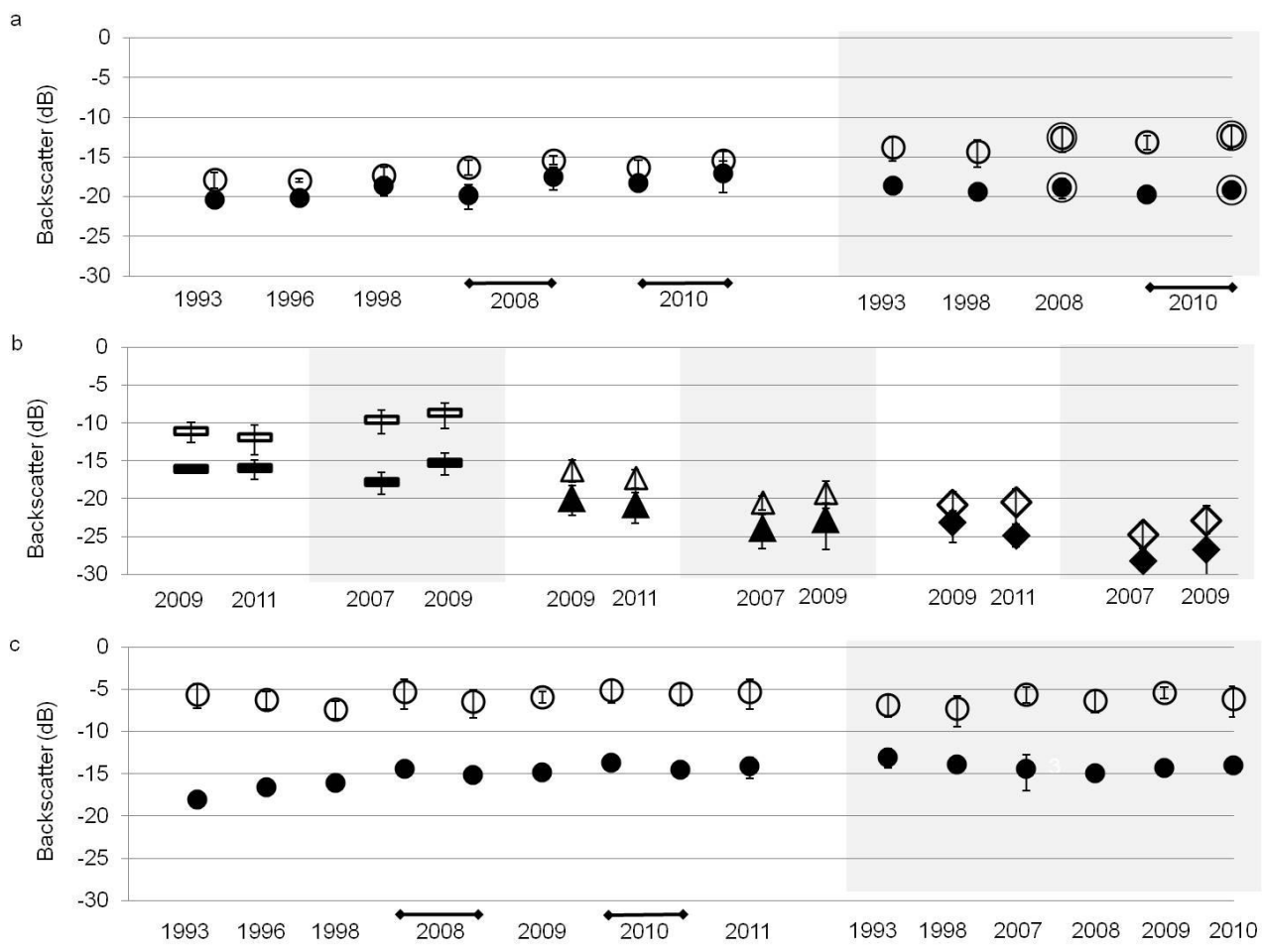

Fig. 4. Mean SAR intensity backscatter values in decibels from floating lake ice (open symbols) and grounded lake ice (closed symbols) from (a) L-band HH from JERS-1 and PALSAR, (b) L-band quad-pol from PALSAR coherency matrix elements $T 11$ (rectangles), $T 22$ (triangles) and $T 33$ (diamonds) that indicate double-bounce, volumetric scattering, and roughness, respectively, (c) C-band VV from ERS-1 and ERS-2. Incidence angles are (a) 39-40 degrees except 24 degrees as noted by concentric circles, (b) 23 degrees, and (c) 24 degrees. Shaded areas highlight lake ice from the northern Seward Peninsula (NSP) and white areas highlight lake ice from the Alaska Arctic Coastal Plain (ACP). Mean backscatter values are from spring lake ice (late March-April) from study lakes outlined in Fig. 1. Error bars represent standard deviation.

postulated that the roughness involved the ice-water interface, our results here show the substantial decrease in $T 11$ backscatter intensity from floating to grounded ice, which provides evidence for the first time that the roughness comes from a rough ice-water interface.

A rough ice-water interface could be caused by uneven ice growth, which can be the result of uneven snow distribution on the ice surface. The highly effective insulating properties of snow make it an important factor in ice growth (Adams and Roulet, 1980; Duguay et al., 2003; Jeffries et al., 2005). Often, wind removes snow from parts of ice-covered lakes and causes snow to drift deeper in other parts. This patchwork of bare ice and snow-covered ice produces areas where ice grows more slowly under insulating snow and more rapidly with less or no snow cover, creating an uneven ice-water interface on the scale of meters.

The cause of a rough ice-water interface could also be explained by ebullition bubbles. Ebullition activity can cause roughness at the ice water interface in two distinct ways. First, as bubbles come to rest under the ice, they cause a rough ice-water interface by creating a pocked water surface, similar to standing waves (Engram et al., 2012). Secondly, as seen in the results of our ebullition simulation experiment at O'Grady Pond, bubbles that are frozen in the ice cause slower ice growth directly beneath the bubble column, leading to the formation of steep domes of ice that are filled with water (Fig. 6). These upward-pointing conic and dome shaped "tents" along the bottom surface of the ice were measured up to $4 \mathrm{~cm}$ in height in our field experiment, and have been observed $1-30 \mathrm{~cm}$ tall in the bottoms of ice blocks harvested over natural ebullition seeps as well. These "tents" are either filled with water or with gas from subsequent ebullition events, causing roughness.

Polarimetric element $T 11$, indicating roughness as the scattering mechanism, was significantly higher in lakes on the NSP compared to the ACP region. Floating-ice L-band single-pol $\mathrm{HH}$ was also significantly higher from lakes on the NSP $(-9 \mathrm{~dB})$ than from floating lake ice on the ACP $(-12 \mathrm{~dB})$. One reason for higher backscatter in the roughness component from NSP lake ice could be the higher rate of ebullition bubbling from lakes in the NSP area compared to ebullition bubbling from ACP lakes (Engram et al., 2012; Walter Anthony et al., 2012; Walter Anthony and Anthony, 2013). The findings that L-band single-pol and $T 11$ 


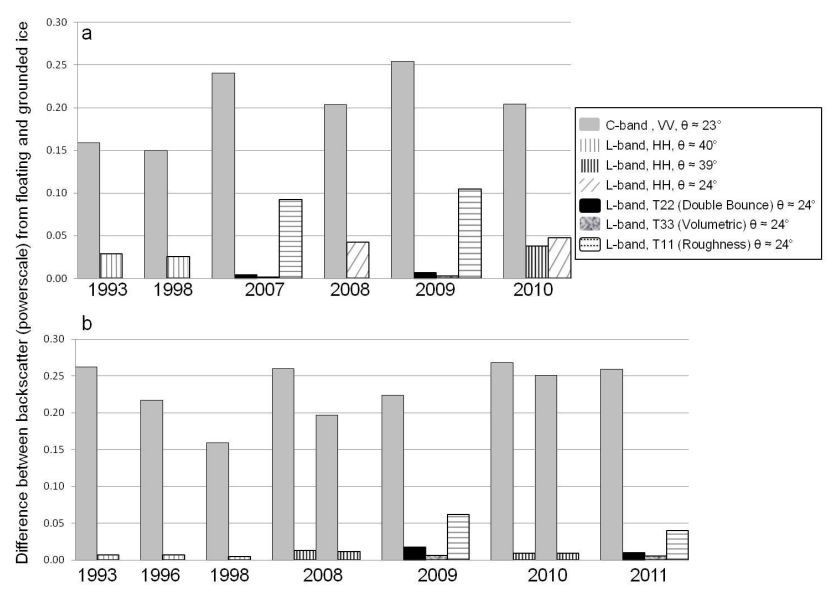

Fig. 5. Difference in SAR intensity between floating and grounded ice for (a) northern Seward Peninsula (NSP) and (b) Arctic Coastal Plain (ACP). The $T 11$ component from polarimeteric decomposition of quad-pol L-band data indicates that roughness is the dominant scattering mechanism for floating ice for L-band, and is greater in NSP than ACP. C-band clearly shows a larger difference between floating and grounded ice for both regions.

roughness component from floating ice are higher in the NSP then the ACP corroborate the relationship between Lband backscatter and methane flux documented by Engram et al. (2012).

The fact that SAR backscatter was very low $(-19 \mathrm{~dB})$ from grounded ice for L-band $\mathrm{HH}$ is most likely explained by the low dielectric contrast at the ice-soil interface on the lake bottom. This has been well documented in studies of uncalibrated airborne L-band radar return (Elachi et al., 1976; Weeks, 1978). In the case of grounded lake ice, microwaves pass through snow and lake ice, but with no liquid-phase water to provide a high dielectric contrast, most of the radar is absorbed by the lake bed instead of reflecting back to the satellite.

For L-band, the signal from grounded ice was a combination of mostly roughness $(-16 \mathrm{~dB})$ with some contribution from double-bounce $(<-20 \mathrm{~dB})$, while volumetric scattering was negligible $(\leq-25 \mathrm{~dB})$, indicating that volumetric scattering from ice itself, in the absence of liquid water below the ice, is close to the noise level of the data (Fig. 4b). This relatively higher L-band $T 11$ roughness backscatter from grounded lake ice could be explained by a reflection from the lake bed. Both regions have fine-grained sediments, as observed by field observations of lake cores in both regions. The small contribution from $T 22$ (double-bounce) could be explained by L-band reflecting from the lake bed, then reflecting again from bubbles in the lake ice.

We found the single-pol L-band backscatter from grounded ice $(-19 \mathrm{~dB})$ to be lower than that in C-band $(-14$ to $-15 \mathrm{~dB}$ ). The lower response of L-band vs. C-band from grounded ice is expected, due to the higher penetration power

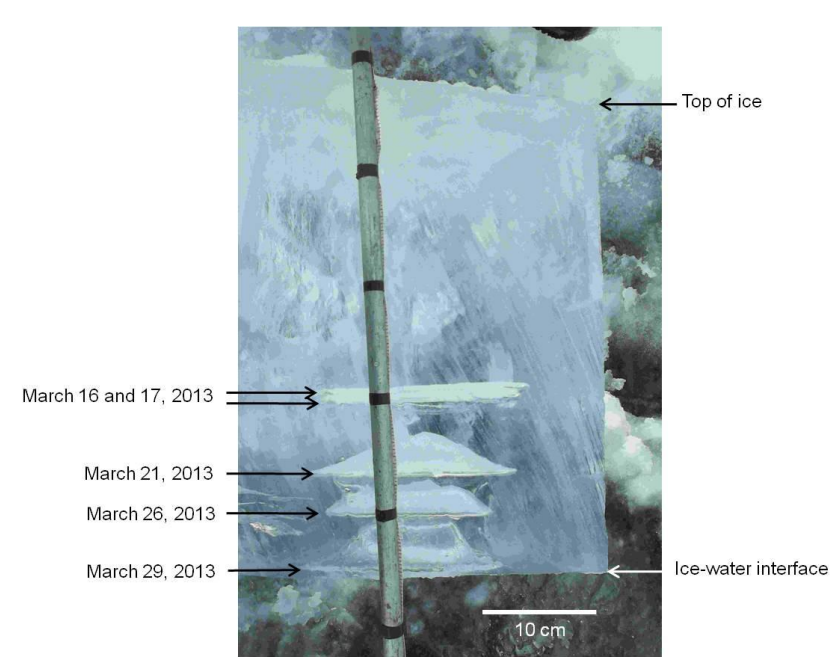

Fig. 6. Results of ebullition simulation in a controlled lake-ice environment. Flat gas pockets sealed in the ice formed from ebullition events on 16 March and 17 March 2013. Subsequently, the topology of the lower ice surface warped into concave, dome-shaped "tents" due to ice growing at a relatively slower rate directly beneath the stack of gas pockets. Ebullition events on 21 and 26 March displaced lake water in the tents and filled the tents with gas. No further ebullition events occurred, yet the bottom surface of the lakeice sheet was rough, with a $4 \mathrm{~cm}$ indentation filled with lake water when this ice block was removed from the lake on 29 March 2013.

of the longer L-band wavelength: penetration distance into a medium is wavelength dependent with the longer wavelength of L-band penetrating deeper than the shorter C-band wavelength. (Ulaby et al., 1986). Another explanation for lower Lband response from grounded ice could be that C-band was reflecting from inclusions in the ice, such as tubular bubbles, that may be too small to create a significant scattering contribution in L-band.

\section{The potential of L-band for detecting grounded and floating ice}

A large difference between backscatter intensity from floating and from grounded ice allows a more accurate discrimination between these two ice regimes. $T 11$ shows a higher contrast than single-pol HH (Fig. 5) and is therefore the most useful parameter for L-band SAR to determine whether lake ice is floating or grounded. While the backscatter intensity from $T 11$ is the same from grounded ice in both regions, this $T 11$ roughness component from floating ice shows interregion variability. This means that in some regions, $T 11$ could be used to differentiate grounded and floating ice but in other regions the difference between grounded and floating ice is only slightly larger than the variance of these two means (Fig. 4b), and L-band would be a poor discriminator. We attribute the inter-regional variability in $T 11$ contrast to differences in ebullition in the two regions. The NSP average 


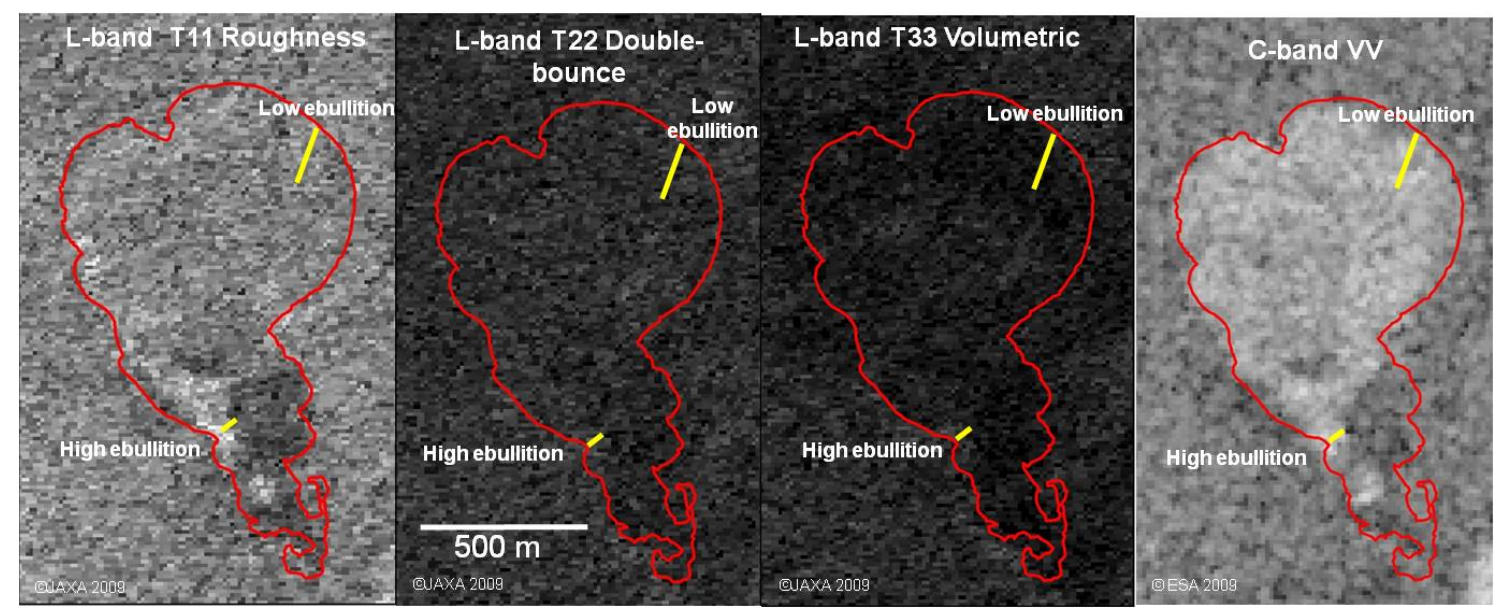

Fig. 7. A frozen thermokarst lake on the Seward Peninsula with floating ice on northern portion of lake and grounded ice at the southern portion shown in L-band $T 11, T 22, T 33$, and C-band VV images acquired on 29 March 2009. The T11 roughness component of quad-pol L-band shows some contrast between floating and grounded ice, but it also shows high absolute backscatter, seen as bright areas from highmethane ebullition areas, as determined by field measurements (yellow lines) in October 2008 (Engram et al., 2012). C-band VV shows the strongest contrast between floating and grounded lake ice. Area marked as high ebullition had $11.1 \%$ area of transect with ebullition gas bubbles, low ebullition had $5.1 \%$ of transect area containing bubbles.

ebullition seep density was 1.8 seeps-meter ${ }^{-2}$ while the density of methane ebullition gas seeps in the ACP was sparser at 0.4 seeps-meter ${ }^{-2}$.

The difference in magnitude of C-band backscatter between floating and grounded ice was five to thirty-six times higher than the floating-to-grounded ice difference in singlepol L-band (Fig. 5), mostly due to the very high backscatter intensity $(-6 \mathrm{~dB})$ from floating ice in C-band. This greater contrast between floating and grounded ice makes C-band $\mathrm{VV}$ a more useful tool to distinguish grounded from floating lake ice than L-band SAR. Even the L-band parameter that showed the highest contrast between floating and grounded ice, the $T 11$ roughness component, showed less than half of the contrast than C-band VV showed between floating and grounded ice.

One factor that affects the utility of L-band for distinguishing grounded vs. floating ice is that it is sensitive to ebullition bubbles trapped by lake ice. In a study of lakes containing different levels of ebullition activity, Engram et al. (2012) observed a positive correlation between backscatter and abundance of ebullition bubbles associated with lake ice for L-band single-pol and the roughness component in the Pauli decomposition (analogous to $\sqrt{T 11}$ ). Similarly, we found higher backscatter in these L-band parameters from high ebullition areas within individual lakes. Figure 7 shows examples of the L-band responses to ebullition and grounded ice in one NSP lake. This higher L-band backscatter response from lake ice with a higher percent area of trapped ebullition bubbles confounds a clear distinction between floating and grounded lake ice. Conversely, grounded lake ice can be a confounding factor for detecting and quantifying ebullition activity in lakes using L-band SAR. The artifact of grounded ice in ebullition research can be avoided by omitting lakes that show a spring decrease in backscatter.

\section{Conclusions}

The average backscatter intensity of L-band HH SAR in March is $-13 \mathrm{~dB}$ for floating ice from the northern Seward Peninsula, $-16 \mathrm{~dB}$ from floating lake ice on the Arctic Coastal Plain, and $-19 \mathrm{~dB}$ for grounded ice from both regions. The dominant L-band scattering mechanism for floating lake ice is primarily roughness which occurs at the icewater interface, as indicated by the strong backscatter from the $T 11$ polarimetric component that decreases when ice freezes completely to the lake bed and liquid water disappears.

To discriminate floating from grounded ice using L-band data, extracting the roughness scattering component $(T 11)$ from polarimetric radar data is recommended. This roughness component achieved decent contrast between floating and grounded ice in our test areas, especially in the northern Seward Peninsula. However, the variance of L-band backscatter from floating ice between regions with different methane ebullition activity make L-band a questionable discriminator of floating and grounded ice for all geographic regions. C-band VV is preferable over L-band SAR data (either single-pol or decomposed quad-pol SAR) for distinguishing lake-ice regimes because it shows greater contrast between floating and bed-fast ice and because the sensitivity of Lband to ebullition bubbles could confound the freeze-to-thebottom signal. 
Acknowledgements. We acknowledge the Alaska Satellite Facility (ASF), both the NASA's Distributed Data Archive Center and JAXA's (Japan Aerospace exploration Agency's) Americas ALOS Data Node for access to SAR data. Access to field sites on the Bering Land Bridge National Preserve was granted by the National Parks Service (permit \# BELA-2008-SCI-0002). Thanks to two anonymous reviewers whose comments helped strengthen an earlier version of the manuscript. Funding was provided by NASA Carbon Cycle Sciences NNX08AJ37G and NNX11AH20G and NSF ARC IPY \#0732735.

Edited by: D. Hall

\section{References}

Adams, W. and Roulet, N.: Illustration of the roles of snow in the evolution of the winter cover of a lake, Arctic, 100-116, 1980.

Arp, C. D., Jones, B. M., Urban, F. E., and Grosse, G.: Hydrogeomorphic processes of thermokarst lakes with grounded-ice and floating-ice regimes on the Arctic coastal plain, Alaska, Hydrol. Process., 25, 17, doi:10.1002/hyp.8019, 2011.

Arp, C. D., Jones, B. M., Lu, Z., and Whitman, M. S.: Shifting balance of thermokarst lake ice regimes across the Arctic Coastal Plain of northern Alaska, Geophys. Res. Lett., 39, L16503, doi:10.1029/2012g1052518, 2012.

Boereboom, T., Depoorter, M., Coppens, S., and Tison, J.-L.: Gas properties of winter lake ice in Northern Sweden: implication for carbon gas release, Biogeosciences, 9, 827-838, doi:10.5194/bg9-827-2012, 2012.

Brown, L. C. and Duguay, C. R.: The response and role of ice cover in lake-climate interactions, Prog. Phys. Geogr., 34, 671-704, doi:10.1177/0309133310375653, 2010.

Cloude, S. R. and Pottier, E.: A review of target decomposition theorems in radar polarimetry, IEEE T. Geosci. Remote, 34, 498-518, 1996

Duguay, C. R., Pultz, T. J., Lafleur, P. M., and Drai, D.: RADARSAT backscatter characteristics of ice growing on shallow sub-Arctic lakes, Churchill, Manitoba, Canada, Hydrol. Proc., 16, 16311644, doi:10.1002/hyp.1026, 2002.

Duguay, C. R., Flato, G. M., Jeffries, M. O., Menard, P., Morris, K., and Rouse, W. R.: Ice-cover variability on shallow lakes at high latitudes: model simulations and observations, Hydrol. Proc., 17, 3465-3483, doi:10.1002/hyp.1394, 2003.

Elachi, C., Bryan, M. L., and Weeks, W. F.: Imaging Radar Observations of Frozen Arctic Lakes, Remote Sens. Environ., 5, 169175, doi:10.1016/0034-4257(76)90047-x, 1976.

Engram, M., Anthony, K. W., Meyer, F. J., and Grosse, G.: Synthetic aperture radar (SAR) backscatter response from methane ebullition bubbles trapped by thermokarst lake ice, Can. J. Remote Sens., 38, 667-682, doi:10.5589/m12-054, 2012.

Farquharson, Louise M.: Sedimentology of Thermokarst Lakes Forming Within Yedoma on the Northern Seward Peninsula, Ph.D. diss., University of Alaska Fairbanks, 2012.

French, N., Savage, S., Shuchman, R., Edson, R., Payne, J., and Josberger, E.: Remote sensing of frozen lakes on the North Slope of Alaska, Geoscience and Remote Sensing Symposium, 2004. IGARSS '04. reProceedings, 2004 IEEE International, 3005, 3008-3011, 2004.
Gao, G.: Statistical Modeling of SAR Images: A Survey, Sensors, 10, 775-795, doi:10.3390/s100100775, 2010.

Gow, A. J. and Langston, D.: Growth history of lake ice in relation to its stratigraphic, crystalline and mechanical structure, U.S. Army, Corps of Engineers, Cold Regions Research and Engineering Laboratory, Hanover, New Hampshire, 24 pp, 1977.

Grosse, G., Jones, B., and Arp, C.: 8.21 Thermokarst Lakes, Drainage, and Drained Basins, in: Treatise on Geomorphology, edited by: Editor-in-Chief: John, F. S., Academic Press, San Diego, 325-353, 2013.

Hall, D. K., Fagre, D. B., Klasner, F., Linebaugh, G., and Liston, G. E.: Analysis of ERS-1synthetic-aperture-radar data of frozen lakes in northern Montana and implications for climate studies, J. Geophys. Res.-Ocean, 99, 22473-22482, 1994.

Hirose, T., Kapfer, M., Bennett, J., Cott, P., Manson, G., and Solomon, S.: Bottomfast ice mapping and the measurement of ice thickness on tundra lakes using C-band synthetic aperture radar remote sensing, J. Am. Water. Resour. As., 44, 285-292, doi:10.1111/j.1752-1688.2007.00161.x, 2008.

Hopkins, D. M.: The Espenberg Maars: a record of explosive volcanic activity in the Devil Mountain-Cape Espenberg area, Seward Peninsula, Alaska, in: The Bering Sea Land Bridge National Preserve: an archeological survey, edited by: Schaaf, J. M., National Park Service, Alaska Regional Office, 262-321, 1988.

Jeffries, M. O., Morris, K., Weeks, W. F., and Wakabayashi, H.: Structural and stratigraphic features and ERS-1 syntheticaperture radar backscatter characteristics of ice growing on shallow lakes in NW Alaska, winter 1991-1992, J. Geophys. Res.Ocean, 99, 22459-22471, 1994.

Jeffries, M. O., Morris, K., and Liston, G. E.: A method to determine lake depth and water availability on the north slope of Alaska with spaceborne imaging radar and numerical ice growth modelling, Arctic, 49, 367-374, 1996

Jeffries, M. O., Morris, K., and Duguay, C. R.: Lake ice growth and conductive heat flow in central Alaska, Arctic Science Conference Abstracts, 53, 120, 2002.

Jeffries, M. O., Morris, K., and Duguay, C. R.: Lake ice growth and decay in central Alaska, USA: observations and computer simulations compared, Ann. Glaciol., 40, 195-199, 2005.

Jones, B. M.: Spatiotemporal Analysis of Thaw Lakes and Basins, Barrow Peninsula, Arctic Coastal Plain of Northern Alaska., M. A., Department of Geography, University of Cincinnati, Cincinnati, 105 pp., 2006.

Jorgenson, M. T. and Shur, Y.: Evolution of lakes and basins in northern Alaska and discussion of the thaw lake cycle, J. Geophys. Res.-Earth, 112, F02s17, doi:10.1029/2006jf000531, 2007.

Jorgenson, T., Yoshikawa, K., Kanevskiy, M., Shur, Y., Romanovsky, V. E., Marchenko, S., Grosse, G., Brown, J., and Jones, B. M.: Permafrost Characteristics of Alaska, Permfrost map of Alaska, Ninth International Conference on Permafrost at University of Alaska Fairbanks, 2008.

Leconte, R., Daly, S., Gauthier, Y., Yankielun, N., Bérubé, F., and Bernier, M.: A controlled experiment to retrieve freshwater ice characteristics from an FM-CW radar system, Cold Regions Sci. Technol., 55, 212-220, doi:10.1016/j.coldregions.2008.04.003, 2009.

Lee, J.-S. and Pottier, E.: Polarimetric Radar Imaging: From Basics to Applications, CRC Press Taylor \& Francis Group, Boca Raton, Fl., 2009. 
Mellor, J.: Bathymetry of Alaskan Arctic Lakes: A key to resource inventory with remote sensing methods, Ph.D. diss, Institute of Marine Science, University of Alaska, 1982.

Morris, K., Jeffries, M. O., and Weeks, W. R.: Ice processes and growth history on Arctic and sub-arctic lakes using ERS-1 SAR data, Polar Record, 31, 115-128, 1995.

Sellmann, P. V., Weeks, W. F., and Campbell, W. J.: Use of Side-Looking Airborne Radar to Determine Lake Depth on the Alaskan North Slope, Special Report No. 230. Hanover, New Hampshire: Cold Regions Research and Engineering Laboratory, 1-10, 1975.

Skolunov, A. V.: Frequency-temperature curve of the complex dielectric constant and refractive index of water, Fibre Chemistry, 29, 367-373, 1997.

Surdu, C. M., Duguay, C. R., Brown, L. C., and Fernández Prieto, D.: Response of ice cover on shallow lakes of the North Slope of Alaska to contemporary climate conditions (19502011): radar remote sensing and numerical modeling data analysis, The Cryosphere Discuss., 7, 3783-3821, doi:10.5194/tcd-73783-2013, 2013.

Ulaby, F. T., Moore, R. K., and Fung, A. K.: Radar remote sensing and surface scattering and emission theory, Microwave remote sensing : active and passive, edited by: Ulaby, F. T., Artech House, Inc., Norwood, Mass., 608 pp., 1982, 1986.

van Zyl, J. J., and Kim, Y.: Synthetic Aperture Radar Polarimetry, 1st ed., JPL Space Science and Technology Series, edited by: Yuen, J. H., John Wiley \& Sons, Inc., Hoboken, New Jersey, 288 pp., 2010.
Walsh, S. E., Vavrus, S. J., Foley, J. A., Fisher, V. A., Wynne, R. H., and Lenters, J. D.: Global patterns of lake ice phenology and climate: Model simulations and observations, J. Geophys. Res.Atmos., 103, 28825-28837, doi:10.1029/98jd02275, 1998.

Walter Anthony, K. M., and Anthony, P.: Constraining spatial variability of methane ebullition in thermokarst lakes using point-process models, J. Geophys. Res.-Biogeosci., 118, doi:10.1002/jgrg.20087, 2013.

Walter Anthony, K. M., Anthony, P., Grosse, G., and Chanton, J.: Geologic methane seeps along boundaries of Arctic permafrost thaw and melting glaciers, Nat. Geosci., 5, 419-426, doi:10.1038/ngeo1480, 2012.

Weeks, W. F., Sellmann, P., and Campbell, W. J.: Interesting features of radar imagery of ice covered north slope lakes, J. Glaciol., 18, 129-136, 1977.

Weeks, W. F., Fountain, A. G., Bryan, M. L., Elachi, C.: Differences in Radar Return From Ice-Covered North Slope Lakes, J. Geophys. Res., 83, 4069-4073, 1978.

Weeks, W. F., Gow A. J., and Schertler, R. J.: Ground-truth observations of ice-covered North Slope lakes imaged by radar, Report No. 81-19. Hanover, New Hampshire: Cold Regions Research and Engineering Laboratory, 1-17, 1981.

West, J. J. and Plug, L. J.: Time-dependent morphology of thaw lakes and taliks in deep and shallow ground ice, J. Geophys. Res.Earth, 113, F01009, doi:10.1029/2006jf000696, 2008.

White, D. M., Prokein, P., Chambers, M., Lilly, M. R., and Toniolo, H.: Use of synthetic aperture radar for selecting Alaskan lakes for winter water use, J. Am. Water Resour. Ass., 44, 276-284, doi:10.1111/j.1752-1688.2007.00160.x, 2008. 